\title{
1. Tychism versus Determinism
}

Although Peirce sometimes calls his philosophical position "Critical Common-sensism," he knew that not all "common-sense" opinions are helpful in the task of finding out the truth. Hence he uses the word "critical." Sound philosophy must take "common-sense" convictions seriously, but must not be led down the garden path by a naive trust in what seems obvious. Those common-sense positions which can stand up under scrutiny are philosophy's pure gold; those which cannot are its dross. The dross not only contributes nothing positive to the enterprise but can seriously hinder any further progress by blocking the road to inquiry. One such uncritical common-sense opinion prevalent in Peirce's day was the conviction "which makes the real things in this world blind unconscious objects working by mechanical laws together with consciousness as idle spectator" (7.559). This position takes for granted, even as self-evident, "that every event is precisely determined by general laws" (1.132, emphasis added). Peirce proposed to submit this "necessitarian" dogma to the test of criticism.

Necessitarianism has taken many forms throughout the history of philosophy and it would be well to state more exactly what brand Peirce's attack was aimed at. It is what he calls "mechanical philosophy" or materialism.

Whoever holds that every act of the will as well as every idea of the mind is under the rigid governance of a necessity coordinated with that of the physical world will logically be carried to the proposition that minds are part of the physical world in such a sense that the laws of mechanics determine anything that happens according to immutable attractions and repulsions. (6.38)

Peirce calls this "the usual and most logical form of necessitarianism."1

1 Alternate forms of necessitarianism, less usual in Peirce's day because they involve so many logical difficulties, are the numerous versions of Descartes' dualism. 
Peirce claims that the necessitarian viewpoint arose in the first place because so many of the great metaphysicians had been mathematicians, and so, understandably enough, made mathematics the model of metaphysics. The Ionians, Pythagoreans, and Platonists, in early times, the Cartesians and Newtonians, in modern times, all explicitly looked to the ideal of rigid demonstration from first principles as normative in any and every scientific undertaking, physical and philosophical $(1.130,1.400)$. Since the discovery of non-Euclidean geometry, however, the status of mathematic's first principles has been somewhat revised, namely, from what was self-evidently true to postulates of a logical system. It had always been recognized, of course, that mathematical first principles were never strictly and exactly confirmed by observation $(1.30,1.400 \mathrm{ff}$.) but that had been put down simply to faulty measurement. If, however, the first principles of Euclidean geometry are only postulates of a system, and if different assumptions will yield different but equally valid geometries, there is no $a$ priori reason to expect that first principles are true of the world at all, much less exactly true of it. That is a question to be decided by observation, and all experimental evidence points to the conclusion that all such mathematical principles are only approximated in the physical world, not simply because methods of measurement are crude but because the world itself does not quite fit the mathematical mold. ${ }^{2}$ The more refined the means of measurement become, the more evident it becomes that there will always be some inexactitude because what is being measured is continuous while exact measurement supposes discrete units (cf. 1.130, 1.400, 6.45).

Peirce argues, therefore, that since exactitude is despaired of even by mathematicians, it can no longer be hoped for in metaphysics. That is to say, no metaphysical first principle can be expected to be more than an approximation of how things are in the world. Consequently, common sense has no longer any right to assume that every

2 In a rejoinder to Dr. Paul Carus' defense of necessitarianism, Peirce distinguishes between mathematics' ideal constructions and physical laws. The former are exact only insofar as they are analytic; the latter, because they come from experience through ampliative inference, can only be approximative. If, and insofar as, ideal mathematical constructions can be interpreted in a physical system, their application to the real world can only be approximate (6.595). 
event is precisely determined by law. Rather, common sense ought to expect just the opposite. A critical examination into the arguments usually given by philosophers in support of the necessitarian thesis must be undertaken.

Peirce classifies the arguments under three general headings: (1) absolute determinism is a postulate of scientific reasoning; (2) it is supported by observational evidence; and (3) it is supported by various $a$ priori reasons. The first class of arguments is based upon a faulty analysis of the logic of scientific reasoning; the second is simply gratuitously asserted; and the third does not take into account various theories of chance forcefully argued from Aristotle down to Peirce.

What are we to think of the contention that absolute determinism is a postulate of scientific reasoning? ? $^{3}$ In the first place, even if it were a postulate of scientific reasoning that would not make it true, nor would it afford any solid reason for thinking that it may be true. It would merely be the expression of a hope that it may be the case (6.39). In practical matters, of course, in cases where a decision to act must be taken, it is legitimate to assume certain things to be true, because if they are not true there would be no reason to act in one way rather than in another. But, Peirce contends, in these cases what is assumed as true is always some individual fact, never an absolutely universal principle:

... it is manifest that no universal principle can in its universality be comprised in a special case or can be requisite for the validity of any ordinary inference. (6.39)

In other words, what is at issue here is the justification of valid induction and a judgment as to what can be expected of such argumentation. On the one hand, Peirce seems to be saying, no particular instance of a general ever exhausts that general nor contains in it the general's generality. How, then, from a limited sample could one ever hope to draw an absolutely exact general principle? An approximation, yes, but that is not what is at stake. On the other hand, if some postulate were required for the most simple and ordinary type of inference, how would we be able to begin reasoning in the first place?

3 See 3.632-635 for Peirce's discussion of the terms "postulate" and "presupposition" which appeared in Baldwin's Dictionary of Philosophy and Psychology. 
Would we have to wait until someone supplied us with the latent major premise? ${ }^{4}$ Is that premise innately known? Is it unknown but operative in our reasoning anyway? But then in what sense could it be said to be reasoning at all, since reasoning supposes control over the process and hence awareness of the premises? Or perhaps what is meant by the defenders of the postulate theory is that the postulate is not strictly speaking a hidden premise of our reasoning but a condition for our reasoning discovered when we make a reflexive analysis of reasoning (logica utens). This last possibility makes sense, but then the question is reduced to what is the correct analysis of scientific reasoning.

Peirce thinks of inference as divided into two major types, explicative and ampliative, a distinction inspired by Kant's syntheticanalytic dichotomy. Deduction is explicative, that is, it does not extend our knowledge of the world but rather enriches our knowledge of the relations among ideas. Induction, hypothesis, and analogy do extend our knowledge of the world. This difference is so fundamental that it dooms to failure any attempt to make induction (and other forms of ampliative reasoning) merely a special kind of deduction. ${ }^{5}$ No doubt the influence of the mathematical model of reasoning is back of this faulty analysis of induction. For Peirce, all nondeductive or ampliative reasoning is based on the same principle and procedure, namely, sampling (6.40). The example he gives is this: from samples of a shipment of wheat (mixed and stirred up with great thoroughness) we find that $\frac{4}{5}$ of the sample contains quality $A$ wheat; therefore, we infer experientially and provisionally, that about $\frac{4}{5}$ of all the grain in the shipment is of the same quality.

By saying that we infer it experientially, I mean that our conclusion makes no pretension to knowledge of wheat-initself, our aletheia, as the derivation of the word implies, has nothing to do with latent wheat. We are dealing only with the matter of possible experience-experience in the full

4 This is the position which those who would reduce induction to a form of deduction must hold.

5 Mill's theory of induction takes "uniformity of nature" as the hidden major premise. See 2.761-767 for Peirce's criticism of Mill. 
acceptation of the term as something not merely affecting the senses but also as the subject of thought. (6.40)

In other words, Peirce is saying that our argument is based only on what we have experienced or can experience of the wheat in future samplings. It excludes from consideration: (a) wheat hidden on the ship that will never turn up, (b) wheat half-hidden in such a way that it may turn up but is less likely to do so than the rest (this situation would alter the randomness of the sampling since it would be false that any grain of wheat has as much chance as any other of turning up in the sample), (c) wheat which can affect our senses or pockets but which cannot be reasoned about (is unknown and unknowable). ${ }^{6}$ Because our reasoning about the wheat is so conditioned by our actual and possible experience of it, our conclusion concerning the true proportion of quality $A$ is drawn only provisionally.

By saying that we draw the inference provisionally, I mean that we do not hold that we have reached any assigned degree of approximation as yet, but only hold that if our experience be indefinitely extended, and if every fact of whatever nature, as fast as it presents itself, be duly applied, according to the inductive method, in correcting the inferred ratio, then our approximation will become indefinitely close in the long run . . . 6.40$)^{7}$

At any given time, then, the inferred ratio is only an approximation of what we will find in future experiences of sampling. That ratio becomes an hypothesis to be verified and/or modified by experience. If experience fluctuates irregularly so that the ratio cannot be assigned any definite value, we can find out approximately within what limits

6 In another paper written a year or so later (1893) Peirce attributed the errors of mechanical philosophy to the "incautious assumption" that there is a difference between "to look red" and "to see red," the assumption of a Ding an sich (7.561).

7 Goudge points out that there is a certain ambiguity in Peirce's use of the term "probable deduction." It sometimes seems to mean necessary reasoning about probabilities; sometimes it seems to mean that the conclusion drawn is only probable, that is, approximately true. $O p$. cit., p. $172 \mathrm{ff}$. 
it fluctuates. If experience changes from one definite ratio to another, we will be able to find that out and modify our approximation.

$\therefore$ and in short, whatever may be the variations of this ratio in experience, experience indefinitely extended will enable us to detect them, so as to predict rightly, at last, what its ultimate value may be, if it have any ultimate value, or what the ultimate law of succession of values may be, if there be any such ultimate law, or that it fluctuates irregularly within certain limits, if it does so ultimately fluctuate. (6.40)

Peirce's contention, therefore, is that what ultimately justifies ampliative reasoning is its self-corrective power (cf. $2.769,5.575 \mathrm{ff}$.), ${ }^{8}$ and that for this reason the inference, claiming to be no more than experiential and provisional, involves no postulate whatever. ${ }^{9}$

On Peirce's analysis every postulate of scientific reasoning is cut off either by the provisionality or by the experientiality of such inference. Any fact which might be supposed postulated, must either be

8 Cf. Goudge, op. cit., pp. 189-190; J. W. Lenz, "Induction as SelfCorrective," Studies, Moore and Robin, pp. 151-162.

9 See Goudge, op. cit., pp. 191-193 for a lengthy discussion of whether or not Peirce's account of induction does not presuppose something like Mill's uniformity of nature after all. He rightly concludes that it does not, and makes a good distinction between Mill's positive assumption about uniformity and Peirce's negative assumption about the intervention of "supernal powers." Undoubtedly it is true that any existential subject matter must be ordered in some way, and no doubt Peirce held this view. Again it is undoubtedly the case that Peirce was convinced that random sampling will find out that order. But would it be accurate to say that the validity of induction depends upon those assumptions, no matter how analytic one would make them? Would it not be enough to say that if there is any order, random sampling will find that out in the long run, and alternately, if there is no definite order, sampling will find that out too? Peirce makes a great deal of the fact that for an induction to be valid the character for which we sample must be predesignated. This means, it seems to us, that we first form an hypothesis as to what regularity we are likely to find or are interested in verifying, and the induction merely confirms or disconfirms it in some ratio. The induction does not suppose antecedently that there is necessarily the order we have assumed in the subject matter. The induction is precisely the method of finding out whether or not the order is there at all and to what degree. 
such that it would ultimately present itself in experience, or would not (6.41). If it will show up in experience, there is no need to postulate it; if it will not show up in experience, it is irrelevant to the validity of our conclusion since the only pretension that conclusion makes is to say what is valid as far as possible experience goes. By linking induction to experience in such a way that experience is allowed to modify the ratio provisionally assigned, induction becomes self-corrective and dependent upon no postulate whatsoever, but only upon future experience.

Peirce sees one important objection to his position, namely, that it does not give induction the full force that it in fact does have. For, on his view, no matter how thoroughly the mixing had been, the examination of a sample would not give any insurance that the next sample would not greatly modify the value of the ratio under inquiry (6.43). Yet as a matter of fact the assurance is very high that the error is not great. Peirce admits that ideally the assurance would be high, but that in most cases we fall somewhat short of perfect conditions. The ideal induction requires that the sampling had been truly random and that the character sampled for had been determined before the sample was examined. These ideals should always be striven for, but when they cannot be perfectly satisfied, provided the induction is carried out honestly, the inference still has some value. Peirce's account was meant to show what that minimum value is, namely, that the process is self-corrective and so will lead to the truth of the matter if persevered in.

Now what about the observational evidence in support of necessitarianism (cf. 6.609)? Peirce does not see how anyone acquainted with scientific research on the inside could take any such claim seriously. Every scientist knows that no observation determines the value of a continuous quantity with a probable error of zero (6.45). But it is objected that this is true only of continuous quantities. What about those continuous quantities that are discontinuous at one or at two limits? Take a line, for instance. We know that it cannot have a length less than zero. Peirce proposes a case where it is a question of determining the length of a line that a certain person had drawn from a marked point on a piece of paper. If we can see no line at all, the observed length is zero; 
$\ldots$ and the only conclusion this observation warrants is that the length of the line is less than the smallest length visible with the optical power employed. (6.45)

To conclude that probably no line had been drawn at all the experimenter would need to have recourse to some indirect evidence such as that the person in question was never near enough to the paper to draw any such line. The general point that Peirce wants to make is that to conclude that some quantity or other is absent from a certain subject matter there must be some experiential evidence, direct or remote, to that effect. It is not enough simply to say that we are unable to detect it. All that we can do in strictest logic in cases where there is no such evidence available is to abstain from any opinion as to the presence of the substance in question (6.45).

Consequently, in Peirce's opinion, not only is there no observational evidence to support the necessitarian view, but all the observational evidence on hand is directly contrary to it. All that the evidence shows is that there is some regularity in nature, a regularity indeed which is anything but exact.

Try to verify any law of nature, and you will find that the more precise your observations, the more certain they will be to show irregular departures from the law. (6.46)

Heisenberg did not enunciate his indeterminacy principle until more than a quarter of a century later (1927), but Peirce would not have been surprised if he had lived to see science so conclude. He certainly would have sided with those who have interpreted the principle to mean that atoms are endowed with a certain spontaneity in their movement against others who attribute the apparent indeterminacy to the intrinsic limitations of measurement techniques.

What most clearly characterizes the universe around us is its enormous variety and diversity $(1.159 \mathrm{ff}$.). But the regularity of law cannot produce irregularity of itself (1.161, $1.174 \mathrm{ff}$.). Even a rather gross, common-sense sort of observation, therefore, supports the thesis that the universe is not the mere mechanical result of blind law (1.162). Only the truly scientific attitude of humble fallibilism allows one to see that this is the case. Synechism is nothing more than fallibilism objectified ( $1.171 \mathrm{ff}$.); in other words, a correct logical analy- 
sis will lead one inevitably to a doctrine of continuity and a doctrine of continuity precludes the possibility of law ever being absolutely precise and exact.

The defenders of rigid determinism, therefore, are driven to $a$ priori reasons to support their case (6.48). They usually argue either that the human mind cannot help thinking that everything is precisely determined by law (6.49), or that this is a natural belief and natural beliefs usually are borne out by experience (6.50), or that absolute chance is inconceivable (6.51), or that, although it may be conceivable, it is unintelligible in the sense that it does not explain the how or why of things, the only justification for any hypothesis (6.52). Peirce does not consider arguments from conceivability or inconceivability to be serious enough to warrant any great attention. The history of ideas and of science has shown all too vividly how precarious a position that is. He thinks that an appeal to "natural belief" is somewhat stronger but still not convincing since the obvious rejoinder is that natural beliefs must be purged through criticism of natural illusions. The genuine natural belief at the bottom of necessitarianism is that there is some regularity in nature. The natural illusion is to think that this regularity is absolutely universal and absolutely exact. The only argument, then, that deserves a closer look is the one which claims absolute chance is not an explanation. The issue to be settled is what is an explanation and when is one required. ${ }^{10}$

Now the paragraphs we have been considering here come from one of a series of five articles which Peirce published in the Monist between 1891 and 1892. This article, entitled "The Doctrine of Necessity Examined," was in fact the second of that series. In the very first article, called "The Architecture of Theories," Peirce briefly took up the question of what required an explanation and concluded:

10 "One of the architectonic -and, therefore, I suppose, by Dr. Carus considered as highly reprehensible-features of my theory, is that, instead of saying off-hand what elements strike me as requiring explanation and what as not doing so, which seems to be his way, I have devoted a long time to the study of the whole logical doctrine of explanation, and of the history of explanations, and have based upon the general principles so ascertained my conclusions as to what things do and what do not require to be explained" (6.612). 
Uniformities are precisely the sort of facts that need to be accounted for. That a pitched coin should sometimes turn up heads and sometimes tails calls for no particular explanation; but if it shows heads every time, we wish to know how this result has been brought about. Law is par excellence the thing that wants a reason. (6.12)

In his detailed reply to Dr. Carus' criticism of Peirce's refutation of necessitarianism, Peirce chides the Monist's editor for saying "offhand" what requires an explanation rather than carefully studying the logical problems involved. If he had, Peirce says, he would not have claimed that absolute chance requires an explanation in terms of law (6.611-612).

First, then, let us see how Peirce defines "explanation" and second, how he arrived at that definition. Something can be called an "explanation" in a strict or in a loose sense. In the loose sense an "explanation" is a "reason." Restricting the term "explanation" to the strict sense, Peirce defines it as

... the replacement of a complex predicate, or one which seems improbable or extraordinary, by a simple predicate from which the complex predicate follows on known principles. (6.612)

A reason, or "explanation" in the loose sense, he defines as

... the replacement of a multiple subject of an observational proposition by a general subject, which by the very conditions of the special experience is predicable of the multiple subject. $(6.612)^{11}$

If these definitions are justified, it follows immediately that only co-

11 Dr. Carus defined "explanation" as a description of a special process of nature in such a way that the process is recognized as a transformation (6.612). To this, Peirce has four major objections: (1) it is not true that special processes of nature are the only things to be explained; (2) an explanation cannot simply be a description of the fact to be explained; (3) not every recognition of a transformation is an explanation, but may indeed itself call for an explanation; and (4) not every explanation as a matter of fact involves the recognition of a transformation, e.g. in certain astronomical explanations. 
incidences or regularities need an explanation and hence law is the thing, par excellence, to be explained.

The analysis which led Peirce to these definitions will be taken from a paper he wrote a few years later (ca. 1901) concerning the logic of history, because it is worked out there in some detail. To begin, he asks what is the psychological sign that an explanation is needed. What spurs us to ask further questions? It is surprise, the emotion we experience when we run into the unexpected (7.189). Is it regularity or irregularity which causes us surprise?

Nobody is surprised that the trees in a forest do not form a regular pattern, or asks for any explanation of such a fact. So, irregularity does not prompt us to ask for an explanation. Nor can it be said that it is because the explanation is obvious; for there is, on the contrary, no explanation to be given, except that there is no particular reason why there should be a regular pattern .... (7.189)

On the other hand, if we were to meet some equally unexpected regularity during our forest stroll, we would start wondering about the explanation. Perhaps this forest is a government conservation project and the trees were planted deliberately in a certain order. The reason for the difference in our reaction to equally unexpected regularity and irregularity is simply this: we are surprised at the regularity because irregularity is "the overwhelming preponderant rule of experience" (7.189). Nature's most obvious characteristic is variety and almost infinite diversity (1.159). Irregularity, then, is not surprising. But, Peirce continues, a breach of an existing regularity does call for explanation. Notice, it is not enough merely to have expected antecedently to investigation some regularity and then to have found only irregularity. In this case we do not demand an explanation of the irregularity which we found but rather revise our reasons for having expected regularity in the first place (7.191).

Let us look at the matter in another way. The whole purpose of science is to find out truth about phenomena, to work out their rationale. The acid test of whether a scientific proposition is true or approaches the truth about phenomena is verification of prediction. Scientific method then looks to making predictions, thus letting us know more or less what to expect. A scientific explanation of a phe- 
nomenon supplies a proposition which, if it had been known before the phenomenon presented itself, would have made it predictable. In other words, a scientific explanation makes the phenomenon a logical consequence, necessary or probable, and so renders it rational. Suppose a die is thrown and it turns up six. Does this fact call for any particular explanation? Not unless there is reason to believe that there are peculiar and pertinent features about that particular throw in which the six turned up. The reason is simply because antecedently to any trial we knew that over the long run it will turn up six about once in six throws (7.192). The case would be very different, however, if a certain die continually turned up six despite the law of probability. We would immediately suspect that it was loaded. In other words, we would immediately seek an explanation because the unexpected had happened. Or again, suppose that on the day of the Lisbon earthquake a new star appeared in the heavens. Does this require a special explanation? The answer again is no. Although it is possible that there is some explanation of the coincidence, it would be foolish to adopt this as a working hypothesis since there is no evidence that there is any connection, this is, antecedently to the event there was no more reason to expect it than not to expect it (7.193). Peirce's conclusion, therefore, is that the only case in which an explanation is called for is when the phenomenon, without some special explanation, would be expected not to present itself (7.194).

In summary, according to Peirce's analysis the following cases require no explanation: (1) sheer irregularity, because it engenders no expectation as to what is likely to turn up, and (2) purely formal regularities (e.g., law of probability), according to which a certain phenomenon is bound to turn up sometime or other in the chance medley of things because these are simply part of the $a$ priori conditions of our knowing randomness at all. The following cases do require an explanation: (1) empirically observed regularities in nature, because they are the exception to the preponderance of experience, (2) breaches in empirically observed regularities, since the regularity has led one to expect certain phenomena to happen and when they do not come to pass, questions must be asked, and (3) failure to discover empirical confirmation of a postulated regularity, and in this case the explanation sought is not precisely why there was no observed regularity but why we were led to postulate it. Explanation, 
then, has to do with the rationality of things and so is in the category of Thirdness. Sheer Firstness and brutal Secondness as such require no explanations because in themselves they are not reasonable. Only when Firstness and Secondness are brought together through the mediation of Thirdness or law are we forced to reason, to ask questions, to inquire, to seek explanations.

The general conclusion to be drawn in the context of Peirce's criticism of necessitarianism is this: law and law alone requires an explanation; consequently, it cannot be posited as the ultimate explanation of the cosmos. Such a position leads to this rather curious sort of reasoning: on the one hand, since law and regularity cannot explain irregularity and growing diversity, the latter are to be set down as inexplicable; on the other hand, since he holds that laws cannot have evolved out of irregularity because they are immutable and ultimate facts, no explanation can be given of them. In short both the regularity and the irregularity of the world are inexplicable (6.60). This is hardly a doctrine sound logic would sanction since it blocks the road to inquiry. The rejection of the hypothesis of absolute chance as a real factor in the universe for a priori reasons leads to a blind alley (see also $1.405 \mathrm{ff}$.).

Necessitarianism, then, stands on no firm ground. It is not a postulate of scientific reason, is not supported by observational data, and leads to a hopeless logical position on a priori arguments. All that remains is for Peirce to give positive reasons for adopting his position. Briefly, they are four: (1) the general prevalence of growth which seems to be opposed to the conservation of energy, (2) the immense variety of the universe, which is chance, and needs no explanation, (3) law, which since it requires an explanation must be explained in terms of something else, namely, chance, and (4) the reality of feeling and consciousness, for which there is no room in a mechanical universe $(6.58-61,6.613)$.

In regard to the first argument, Peirce simply invites the reader to examine any science which deals with the course of time: history, geology, paleontology, astronomy. All testify to growth and increasing complexity. ${ }^{12}$ Death and corruption are merely secondary and accidental phenomena.

12 This is one of the major points made by Teilhard de Chardin in The Phenomenon of Man. 
From these broad and ubiquitous facts we may fairly infer, by the most unexceptionable logic, that there is probably in nature some agency by which the complexity and diversity of things can be increased; and that consequently the rule of. mechanical necessity meets in some way with interference. (6.58)

Peirce tells Dr. Carus that a real understanding of the force of this argument requires a thorough familiarity with the way in which physicists explain nonconservative action in terms of conservative action. ${ }^{13}$ We have already seen how they take refuge in the laws of probability "as preventive of the velocities ever getting reversed" (6.613). Consider again the example of white light refracted through a prism. It is possible for the colored light to be reversed through the prism so as to reconstitute the original white light. But as a matter of fact, without special intervention on the part of the experimenter, this rarely happens because the probabilities are so overwhelmingly against just the right combinations of circumstances being present to bring about the effect. The nonconservative effect of friction and viscosity are similarly explained in terms of probabilities. Peirce's point is that the physicists are calling upon the action of chance to explain these phenomena.

I do no more, then, than follow the usual method of the physicists, in calling in chance to explain the apparent violation of the law of energy which is presented by the phenomena of growth: only instead of chance, as they understand it, I call in absolute chance. (6.613)

The difference between Peirce's interpretation of chance and the usual one of the physicist is that Peirce's makes chance something in nature and not merely a function of our ignorance of an extremely complex causal system. The general principle behind this view is that

... in a broad view of the universe a simulation of a given elementary mode of action can hardly be explained except by supposing the genuine mode of action somewhere has place. (6.613)

13 See the treatment in Part II, Ch. 3. 
Of course, there is no question of strict and absolute proof but merely of which hypothesis is better warranted by logic. The pragmatic maxim and the synechistic rule of logic, based as they are on realism, indicate that we should assume that a simulated violation of the law of energy has a real violation of the same law as its ultimate explanation (6.613).

Now, growth appears to violate the law of energy. To explain it, we must, at least, suppose a simulated, or quasi, chance, such as Darwin calls in to produce his fortuitous variations from strict heredity. (6.613)

Even if it be argued that there is no real violation of the law and no real chance in the immediate phenomenon, must not the conditions upon which the phenomenon depends require real chance? Or it might be argued that the law of conservation of energy is not strictly accurate while the other laws of dynamics are and that therefore there is no absolute chance. But Peirce thinks that physicists would not allow such a distinction and that if the exactitude of the law of energy were called into question all the other laws' exactitude would be questioned too. In that case, mechanical philosophy would have yielded its position. ${ }^{14}$ Add to this the fact that most psychologists

14 Peirce thinks of the laws of dynamics as formal laws or regulative principles used to account for phenomena governed by real forces or material laws. The formal laws are ways of thinking about the phenomena but do not exhaust their reality, and hence the formal laws are never exactly verified. They are really mathematical constructions giving us a way of interpreting observed regularities. These formal laws are not laws of the phenomena, nor do they make the real regularities or material laws any the less real and objective. Thus writing in 1905, Peirce declares: "As to the common aversion to recognizing thought as an active factor in the real world, some of its causes are easily traced. In the first place, people are persuaded that everything that happens in the material universe is a motion completely determined by inviolable laws of dynamics; and that, they think, leaves no room for any other influence. But the laws of dynamics stand on quite a different footing from the laws of gravitation, elasticity, electricity, and the like. The laws of dynamics are very much like logical principles, if they are not precisely that. They say only how bodies will move after you have said what the forces are. They permit any forces, and therefore any motions. . . . Setting dynamical laws to one side, then, as hardly being positive laws, but rather mere formal principles, we have only the laws of gravitation, elasticity, 
will admit the intimate connection between the law of growth and the law of habit, which would be destroyed if it were rigidly obeyed, the phenomenon of growth surely seems to indicate a positive violation of energy's law (6.613).

Peirce invites us next to consider the third argument since it fortifies the first. We have already seen how and why the logic of explanation requires that law or regularity be explained. What Peirce wants to consider here is that among the physical laws which appear to be so different there are analogies which also have to be explained. $\mathrm{He}$ gives as examples gravitation, electricity, and radiation, all of which, despite the differences in the forces involved, obey an inverse square law. This calls for an explanation and as we have seen, if the laws are fundamentally original and absolute, there can be no explanation. The only way out is to suppose that law is not so absolute and that there is real absolute chance (6.613).

As regards the second argument, variety in the universe, insofar as it consists in the unlikenesses between things, calls for no explanation. Still variety is a general characteristic of the world, and its generality needs some explanation. Peirce sees this as the question to be answered:

... whether this manifold specificalness was put into the universe at the outset, whether God created the universe in the infinitely distant past and has left it to its own machinery ever since, or whether there is an incessant influx of specificalness. (6.613)

Peirce sees two alternatives: one can argue that the phenomenon of growth in the universe is limited to certain intervals and to certain parts of the universe, but that the universe as a whole is not growing; or one can argue that the pervasiveness of growth through the cosmos as far as science can tell seems to argue that the whole is constantly growing and constantly has new diversity and variety introduced. This is the position of the evolutionist and, for Peirce, the hypothesis recommended by all sound logic (6.613). The reason is always the

electricity, and chemistry. Now who will deliberately say that our knowledge of these laws is sufficient to make us reasonably confident that they are absolutely eternal and immutable, and that they escape the great law of evolution?" (1.348). 
same: the anti-evolutionist hypothesis renders phenomena ultimately inexplicable and so blocks the road to inquiry.

... to say no process of diversification takes place in nature leaves the infinite diversity of nature unaccounted for; while to say the diversity is the result of a general tendency to diversification is a perfectly logical probable inference. (6.613)

Sound logic prescribes that we may not legitimately conclude to what goes beyond what we observe, except insofar as it explains or accounts for what we observe. The evolutionistic hypothesis does just that. It is no explanation to say that there is diversity in the world because God made it so. This is simply to state the fact that there is diversity in the world, not to give an explanation of how it got there, whether all at once in the beginning or continually throughout time by an evolution. ${ }^{15}$

As to the fourth argument, Peirce contends that necessitarians are embarrassed by the fact of consciousness and must do their best to make up accounts with a reality which by all rights according to their theory should not be real at all. Indeed, they do try to reduce it to some sort of illusion, an illusion of a material system. Colors are

15 Peirce goes on to remark that we do not know God's secret counsels. We only know what He does do, and nothing more. Then he says, "For the same reason one cannot logically infer the existence of God; one can only know Him by direct perception" (6.613). It seems that what Peirce is rejecting is "God as hypothesis" or "the God of the gaps." We agree that one may not call upon the existence of God as a substitute for scientific explanation, but we would have some reservations as to the illegitimacy of inferring the existence of God as ground and goal of phenomena as such. Might not one argue that God is the necessary condition of possibility for there being anything at all? At least we do not see that it is logically impossible. Even Peirce admits that we can legitimately conclude to something beyond what we have observed if it accounts for or explains what we have observed. This would not be necessarily simply to fall back into the "God-of-the-gaps" trap, because the sort of question it seeks to answer is different. It is not a scientific question and so does not require a scientific explanation. It is properly philosophical and addresses itself not merely to the question of understanding a given structure, but to the question of why and how there should be anything at all, even bits of matter swirling at random through space. 
reduced to rates of vibrations; brain matter is nothing more than protoplasm, itself merely an arrangement of mechanical particles, of a certain degree of complexity. All feeling is reduced to some "inward aspect" of matter, to a phantom. Peirce's hypothesis is not so encumbered by observed psychical facts, as empirical as any physical facts, as to be forced to explain them away.

On the other hand, by supposing the rigid exactitude of causation to yield, I care not how little-be it but by a strictly infinitesimal amount-we gain room to insert mind into our scheme, and to put it into the place where it is needed, into the position which, as the sole self-intelligible thing, it is entitled to occupy, that of the fountain of existence; and in so doing we resolve the problem of the connection of soul and body. (6.61)

Now that Peirce has attacked the great redoubt blocking the road to further progress in science and in philosophy, he must sketch in some detail the position he proposes to erect in its place, a position which will help traffic move smoothly and continuously over the road to be travelled by inquirers after the truth. We must, therefore, now follow Peirce in working out his philosophical account of the cosmos as it arises out of absolute chance. 